\title{
CONDIÇÕES DE VIABILIDADE PARA A REGULARIZAÇÃO FUNDIÁRIA PLENA: UMA PROBLEMATIZAÇÃO A PARTIR DA EXPERIÊNCIA DE JUIZ DE FORA (MG)
}

\author{
Laura Santos Granja* \\ Alex Ferreira Magalhães ${ }^{* *}$ \\ *Centro Universitário do Sudeste Mineiro, Curso de Arquitetura e Urbanismo, Juiz de Fora, MG, Brasil \\ **Universidade Federal do Rio de Janeiro, Centro de Ciências Jurídicas e Econômicas, Instituto de Pesquisa e \\ Planejamento Urbano e Regional, Rio de Janeiro, RJ, Brasil
}

\begin{abstract}
Resumo
A partir de uma abordagem de cunho teórico-prático, cuja empiria se baseia na experiência do município de Juiz de Fora (MG) com ações de regularização fundiária, o artigo busca refletir, de maneira contextualizada, sobre o desenho, o processo e o momento "pós-intervenção" da regularização de assentamentos urbanos de baixa renda. Apesar de avaliar que a experiência estudada ficou aquém do atendimento do conceito de regularização fundiária plena, o trabalho sistematiza pressupostos e lições que dela emergiram, propondo algumas balizas para a atualização do conceito e das práticas em questão. É dada atenção especial aos beneficiários da regularização, contrastando a visão recorrente de que eles são meros "parceiros" com a perspectiva que os situa como protagonistas do processo.

Palavras-chave

Regularização fundiária plena; Regularização fundiária urbana; Assentamentos de baixa renda; Avaliação de política pública; Regularização fundiária de interesse social.
\end{abstract}




\title{
CONDITIONS FOR VIABLE FULL LAND TENURE REGULARIZATION: A PROBLEMATIZATION BASED ON THE EXPERIENCE OF JUIZ DE FORA (MG)
}

\author{
Laura Santos Granja* \\ Alex Ferreira Magalhães ${ }^{* *}$ \\ *Universidade Federal do Rio de Janeiro, Departamento de Sociologia, Rio de Janeiro, RJ, Brazil \\ **Universidade do Estado do Rio de Janeiro, Instituto de Estudos Sociais e Políticos, Rio de Janeiro, RJ, Brazil
}

\begin{abstract}
With a theoretical-practical approach, empirically based on experience in the municipality of Juiz de Fora, in the state of Minas Gerais, through actions of land tenure regularization, this paper, in a contextualized manner, seeks to reflect on the design, process and "post-intervention" moment of the regularization of low-income urban settlements. Although it was assessed that the investigated experience failed to meet the concept of full land tenure regularization, the study was nonetheless able to identify a number of assumptions and lessons that emerged, through which it has been possible to propose some relevant guidelines in order to revise the concept and practices under discussion. Special attention has been given to the beneficiaries of the regularization process, thereby contrasting the recurrent view that they are mere "partners" with the perspective that places them rather as protagonists in the process.

Keywords

Full land tenure regularization; Urban land regularization; Low-income settlements; Public policy assessment; Land tenure regularization of social interest.
\end{abstract}




\title{
CONDIÇÕES DE VIABILIDADE PARA A REGULARIZAÇÃO FUNDIÁRIA PLENA: UMA PROBLEMATIZAÇÃO A PARTIR DA EXPERIÊNCIA DE JUIZ DE FORA (MG)
}

\author{
Laura Santos Granja \\ Alex Ferreira Magalhães
}

Introdução

O campo de estudos sobre processos de regularização fundiária urbana no Brasil tem crescido, trazendo, por isso, múltiplas compreensões a respeito do tema. Ao menos três visões principais, cada uma com ênfase em um determinado aspecto, podem ser reconhecidas. A primeira delas caracteriza a regularização fundiária apenas como titulação dos lotes, regularização dominial ou regularização patrimonial. Em outra, o foco é a recuperação urbana do assentamento por meio da urbanização da área. Numa terceira, a grande preocupação é regularização urbanística dos assentamentos (ALFONSIN, 2007). Buscando integrar esses três aspectos, foi concebido o conceito de regularização fundiária plena:

\footnotetext{
Regularização fundiária é um processo conduzido em parceria pelo Poder Público e população beneficiária, envolvendo as dimensões jurídica, urbanística e social de uma intervenção que, prioritariamente, objetiva legalizar a permanência de moradores de áreas urbanas ocupadas irregularmente para fins de moradia e, acessoriamente, promove melhorias no ambiente urbano e na qualidade de vida do assentamento, bem como incentiva o pleno exercício da cidadania pela comunidade sujeito do projeto (ALFONSIN, 2007, p.78).
}

Além das dimensões jurídica, físico-social e urbanística, com a promulgação da Lei Federal nº 11.977 em 2009, uma outra foi enunciada: a dimensão ambiental. 
Isso induziu a atualização do conceito de regularização fundiária plena. 0 art. $46^{1}$ da referida lei estabelecia que

[a] regularização fundiária consist[ia] no conjunto de medidas jurídicas, urbanísticas, ambientais e sociais que visa[va]m à regularização de assentamentos irregulares e à titulação de seus ocupantes, de modo a garantir o direito social à moradia, o pleno desenvolvimento das funções sociais da propriedade urbana e o direito ao meio ambiente ecologicamente equilibrado (BRASIL, 2009, grifos nossos).

Dessa forma, as políticas de regularização fundiária plena, concebidas por meio de uma noção pluridimensional, representam uma das principais apostas institucionais no sentido de contribuir para a mitigação do problema da segregação socioterritorial e do acesso à terra urbanizada nas cidades brasileiras.

Uma característica comumente atrelada à regularização fundiária se relaciona a certa ideia de "missão civilizadora”. Nela, a regularização é interpretada como um instrumento capaz de fazer com que os assentamentos de baixa renda, que boa parte da literatura especializada classifica como "informais", funcionem de acordo com as regras da dita cidade formal ou "do asfalto"2. Tal abordagem não percebe as potencialidades dessas áreas, suas características próprias e sua estrutura peculiar, que podem ser também virtudes, e não meras ausências. Assim, na contramão da perspectiva da "missão civilizadora", no presente trabalho, tomamos como ponto de partida a base teórica construída por autores como Ananya Roy (2005; 2011), Janice Perlman (1977), Boaventura de Sousa Santos (1996) e Ana Clara Torres Ribeiro (2005), complementada por outros estudiosos que são citados e articulados ao longo do texto, de modo a auxiliar o aprofundamento da reflexão em torno das concepções e práticas que marcam a regularização fundiária no país.

Ananya Roy (2005) enfatiza a temporalidade e a espacialidade das fronteiras do formal e do informal. A autora afirma que o limiar é flexível e compreende objetos de disputa, arranjos políticos e arbitrariedades. A informalidade engloba o mundo urbano como um todo e, em razão disso, deve ser reconhecida como uma categoria política, especialmente porque a definição de informal depende da capacidade e da modalidade de regulação estatal. Roy (2011) ainda argumenta que

\footnotetext{
1. $O$ art. 46 da Lei Federal no. 11.977 de 2009 foi posteriormente revogado pela Lei Federal $n^{0} 13.465$ de 2017. Entretanto, dada a temática tratada neste texto e sua atualidade e relevância em termos conceituais, consideramos relevante mencioná-lo.

2. Neste texto as aspas duplas podem indicar tanto a citação direta de autores e documentos, quanto expressões do senso comum ou terminologias gerais. O contexto em que são empregadas determinam o sentido ao leitor.
} 
a informalidade precisa ser entendida não como sinônimo de pobreza, mas como uma lógica a partir da qual o valor espacial é produzido e gerenciado. Para romper com a ideia de subalternidade e compreender a heterogeneidade do urbanismo, ela propõe o conceito de espaços cinzas, aqueles espaços que não estão nem integrados à urbe (espaços brancos), nem excluídos dela (espaços pretos), marcando a pseudopermanência dessas áreas na marginalidade. Yiftachel (2011, p. 153, tradução livre) explica que “a identificação do 'espaço cinza' como um incessante processo de 'produção' das relações sociais contorna a falsa dicotomia modernista entre 'legal' e 'ilegal', ‘oprimido’ e ‘subordinado', ‘fixo’ e ‘temporário”' - polarizações ainda não superadas.

Ao longo de seu processo de consolidação, os assentamentos de baixa renda receberam rótulos sociais e políticos impostos pelas classes hegemônicas, e os interesses econômicos reforçaram os preconceitos: “O que era considerado normal ou marginal acabou por ser determinado menos pelo comportamento da maioria ou da minoria numérica, e mais pelo que é feito especificamente pelas classes média e alta” (PERLMAN, 1977, p.124-125). Segundo a escola arquitetônico-ecológica, como elucida Perlman, a marginalidade é compreendida como algo a ser erradicado materialmente, via remoção dos assentamentos de baixa renda e construção de moradias adequadas pelo governo. Por meio desse caminho, os pobres superariam a sua condição de pobreza - tanto econômica, quanto cultural - e seriam integrados à sociedade mais ampla, passando a usufruir dos direitos e das obrigações decorrentes de seu novo status. Tal modelo de interpretação e de intervenção em favelas revelou-se insustentável sob vários ângulos, uma vez que se revelaram, entre outros aspectos, as enormes complexidades das cirurgias urbanas propostas, junto dos resultados pífios na redução do número de moradores de favelas, apenas para oferecer dois exemplos mais imediatos. As soluções dadas pela própria população foram o repasse dos apartamentos nos conjuntos habitacionais, a persistência das ocupações de terras e o retorno às favelas e à vida na dita informalidade, nos espaços cinzas, desafiando a ordem dominante e excludente. A crítica à teoria da marginalidade, como se infere da obra de Perlman, pôs em questão a noção de integração social, muito presente na literatura especializada na temática da regularização fundiária.

A polarização entre o formal e o informal, o incluído e o excluído, vem sendo também criticada por outros autores. Boaventura de Sousa Santos (1996) apresenta uma abordagem sociojurídica pautada na concepção de pluralismo jurídico, que toma as várias formas do Direito como mapas sociais passíveis de diversas representações. Nesse viés teórico, a questão da formalidade deixa de ser alvo de uma única regra, passando a ser vista a partir de diferentes regras em diferentes escalas. 
Corroborando essa ideia, mas de outro ângulo, Ana Clara Torres Ribeiro (2005) considera o uso do termo informal inadequado para classificar as formas resistentes ou alternativas ao modo dominante de vida urbana. Segundo a autora, o informal carrega uma ideia negativa que pode dificultar a leitura da cidade como campo de possibilidades. "As formas de sociedade, assim como as formas da cidade, são criações a partir das quais novas possibilidades, antes inexistentes, uma vez que privadas de sentido, aparecem” (GIRALDO, 2003 apud RIBEIRO, 2005, p. 28).

No presente artigo, evitamos as polarizações simplificadoras entre formal e informal, regular e irregular, incluído e excluído. Trabalhamos com a premissa de que toda a cidade representa um incessante processo de produção e intercâmbio de territorialidades assimétricas, cabendo à regularização não o papel de conversão de uma na outra, mas de produção de sinergias entre elas.

Seguindo essa narrativa, o processo de regularização fundiária não é tomado como aquilo que vai necessariamente adequar o assentamento à cidade formal e à legalidade. $\mathrm{O}$ que é considerado formal ou legal varia ao longo dos anos e dos contextos sociais, políticos e econômicos. E essas variações não são apenas de enfoque (ou uma questão de maior ou menor especificação), mas também de conteúdo, uma vez que uma regra vigente hoje pode ser totalmente antagônica àquela que lhe antecedeu. Raquel Rolnik (1997) afirma que a irregularidade não se refere a uma determinada configuração espacial, mas a múltiplas delas, todas coexistentes nas cidades. Isso acontece devido à existência de diversos tipos de irregularidades na configuração jurídico-urbanística e ao fato de que as normas jurídicas podem ter, na prática, diferentes significados para os agentes sociais, dependendo das condições políticas e culturais que ditam a construção de seu pensamento (ROLNIK, 1997).

Ao longo do tempo, as leis são passíveis de modificações, e este é um dos motivos que impulsionam os estudos consolidados neste artigo, cujo objetivo principal é sinalizar possíveis correções de rumo na implementação de iniciativas similares, assim como refletir sobre a replicação, em escala ampliada, de programas orientados pelo conceito de regularização fundiária plena. Para subsidiar a reflexão, foi considerada uma abordagem metodológica de cunho teórico-prático, posto que a avaliação de processos de regularização fundiária já implementados pode fornecer indícios de possíveis caminhos a serem seguidos ou evitados no desenho de programas semelhantes.

O artigo parte de uma breve revisão da literatura; em seguida, avança para o estudo empírico, culminando numa determinada reflexão crítica a respeito do conceito de regularização fundiária plena. Na parte empírica, que consiste na avaliação do processo de implementação da política de regularização fundiária e de seus possíveis impactos nas áreas beneficiadas, valemo-nos dos resultados da pesquisa 
desenvolvida entre 2018 e 2019 nos assentamentos Vila Sô Neném, Vila Mello Reis e Alto Santo Antônio, todos localizados em Juiz de Fora, Minas Gerais.

A referida pesquisa incluiu entrevistas e grupos focais com técnicos da prefeitura municipal e da empresa de engenharia licitada para executar o projeto de regularização e com moradores dos assentamentos, além de levantamentos documentais em arquivos públicos ${ }^{3}$. Os três assentamentos foram selecionados de modo a abranger as regiões urbanas com maiores índices de vulnerabilidade e maior quantidade de Áreas de Especial Interesse Social no município. Também foi levada em consideração a facilidade de acesso a participantes do processo de regularização e a arquivos públicos. Em números, foram envolvidos um total de 27 participantes no estudo, sendo $63 \%$ desse total composto de moradores dos assentamentos, $18,5 \%$, de membros da associação de bairro, $15 \%$, de técnicos da prefeitura, e $3,5 \%$, de engenheiros ligados ao processo. Após a finalização do levantamento de dados em campo e da transcrição do material coletado, foram elencados temas mencionados pelos participantes. A partir daí, foi construída a análise apresentada neste artigo (GRANJA, 2019).

\section{Breve notícia da experiência juiz-forana de regularização fundiária}

O município de Juiz de Fora revelou um cenário que destaca a importância das experiências pioneiras para a consolidação de ações e políticas urbanas. Ao término da experiência de regularização na Vila Olavo Costa, em 1985, uma área de baixa renda no município, foi criada a Coordenadoria de Regularização de Parcelamentos (CORE). A CORE promoveu intervenções semelhantes em Juiz de Fora, tendo consolidado e aprimorado suas ações até o momento em que foi substituída por outras estruturas administrativas. Esse fato remete ao processo de consolidação dos instrumentos urbanísticos na política urbana nacional. Muitos dos instrumentos de regularização fundiária que vêm sendo implantados no país desde a década de 1980, antes de serem objeto da legislação federal, foram alvo de experiências pioneiras em municípios que, tendo sido consideradas bem-sucedidas, se difundiram nacional ou internacionalmente. Como exemplo, é possível citar

\footnotetext{
3. Principais levantamentos documentais: JUIZ DE FORA, Prefeitura Municipal. Processo $\mathrm{n}^{0} 000278$ EMCASA regularização das ocupações existentes no final da rua Milton de Araújo Campos, Alto Santo Antônio. Brasil: [s.n.]., 2010; Processo nº 004345 - V1 - Ação de usucapião especial coletivo de imóvel urbano proposta pela associação de moradores da Vila Sô Neném de Juiz de Fora e pelo Município de Juiz de Fora. [s.l.: s.n.]., 2002a.; Processo nº 004345 - V2 - Ação de usucapião especial coletivo de imóvel urbano proposta pela associação de moradores da Vila Sô Neném de Juiz de Fora e pelo Município de Juiz de Fora. Juiz de Fora: [s.n.]., 2002b.; Processo nº 01658 - Licenciamento ambiental - Vila Sô Neném Programa Habitar Brasil. Brasil: Juiz de Fora, 2002.; e Processo nº 02533 - V2 - Lei no 9206 - Dispõe sobre a concessão de uso com direito real resolúvel das áreas públicas constantes do loteamento Vila Mello Reis no bairro Santa Cruz. Juiz de Fora: [s.n.], 1984.
} 
a experiência pioneira do Plano de Regularização das Zonas Especiais de Interesse Social (PREZEIS), consolidado em Recife, ainda em 1983, com a Lei no ${ }^{\circ}$ 14.511. Essa experiência trouxe o instrumento urbanístico das Zonas de Especial Interesse Social (ZEIS), instrumento adotado nacionalmente há pelo menos duas décadas.

Apesar de as experiências estudadas situarem-se num município que, já em 1986, dispunha de uma coordenadoria voltada para a regularização, as ações de regularização não foram vinculadas, por muito tempo, diretamente ao órgão central de planejamento urbano. A condução da política de regularização fundiária ficou a cargo da Empresa Regional de Habitação (EMCASA), a qual não priorizou o planejamento das ações; assim, a regularização foi executada através de medidas emergenciais ou em atendimento a "solicitações políticas". Tal fato sugere que a regularização fundiária em Juiz de Fora talvez tenha sido englobada por relações de clientelismo, pondo em xeque o objetivo de garantir direitos urbanos e territoriais de caráter coletivo.

Dos casos estudados nesse município, dois deles foram alvo de um programa maior de regularização, financiado por organizações internacionais. Nesse sentido, as demandas para o financiamento exigiam uma intervenção envolvendo infraestrutura, titulação e ações ambientais e sociais. Apenas a Vila Sô Neném chegou a ter todos esses componentes figurando no projeto de regularização; entretanto, nem este assentamento pode ser considerado como uma experiência de regularização fundiária plena, isto é, que tenha efetivamente contemplado as quatro dimensões essenciais mencionadas na introdução deste texto, uma vez que os processos de regularização urbanística e edilícia não chegaram a acontecer.

A dificuldade em completar as intervenções provém, inicialmente, de uma dificuldade em alocar recursos para esse fim, acompanhada do baixo número de técnicos da prefeitura municipal dedicados a trabalhar o assunto. Não bastasse isso, a desvalorização do setor de planejamento frente ao setor de obras é outro aspecto relevante que, muitas vezes, dificulta a correta alocação de esforços e recursos. Problemas como esses são comuns nas prefeituras municipais, mas, mesmo diante de tantos entraves, ações de regularização fundiária são executadas. Assim, as prefeituras fazem o que está ao alcance delas, dentro de suas limitações estruturais, administrativas e políticas. É importante destacar, ainda, que, por vezes, a dificuldade está na própria compreensão do que é regularização fundiária. Como revelado por moradores e parte dos técnicos da prefeitura, é comum o entendimento de que a regularização trata apenas a dimensão jurídico-dominial. A ideia da regularização fundiária plena, com suas quatro dimensões articuladas, não é uma compreensão enraizada e aplicada nessa experiência. Na verdade, há 
evidências de que isso se passa em outras municipalidades brasileiras. Em projeto de pesquisa aplicado em escala nacional, entre 2016 e 2018, coordenado por um dos autores deste artigo, foram colhidas amostras da legislação municipal de regularização fundiária urbana em vigor em todos os estados do país. As amostras atestaram a compreensão desarticulada das dimensões da regularização fundiária. A título de exemplo, podemos citar o trabalho de Antão (2017).

A pesquisa empírica revelou tanto as particularidades dos assentamentos onde a regularização se processou quanto as diversas iniciativas promovidas pela prefeitura em torno da situação. Cada um deles foi regularizado por meio de instrumentos jurídicos específicos e contemplou, efetivamente, diferentes dimensões da regularização fundiária. O primeiro assentamento, Vila Sô Neném, localizado na região leste do município, passou por um processo aproximado do que se entende por regularização fundiária plena, o qual se iniciou em 2002 e concluiu-se em 2007, seguido de dois anos de acompanhamento das ações. No caso da Vila Sô Neném, foi aplicado o instrumento da usucapião coletiva para um total de 223 domicílios. O segundo, Vila Mello Reis, área da região norte de Juiz de Fora, se baseou em um processo de titulação através da Concessão de Direito Real de Uso (CDRU) em formato individual para um total de 209 domicílios. Tal processo foi iniciado em 1986 e concluído em 2008, com a entrega aos moradores do título de CDRU registrado em cartório. Por fim, o último assentamento, Alto Santo Antônio, localizado na região sudeste do município e com um total de 290 domicílios, recebeu projeto e obras de infraestrutura entre 2000 e 2007, mas não chegou a acontecer a titulação dos moradores. ${ }^{4}$

\section{Refinando o entendimento da regularização fundiária, na linha de sua concepção 'plena'}

Neste estudo, trabalhamos com a compreensão de que o processo de regularização fundiária possui amplo potencial para impactar positivamente as condições de habitação, atendendo aos interesses dos moradores do assentamento beneficiado, os quais, no campo conceitual, costumam figurar como os principais sujeitos da regularização. No entanto, tal processo não pode ser considerado, de antemão, como uma intervenção que produzirá impacto positivo ou gerará protagonismo político, dado que isso depende de um sem-número de variáveis que intervêm no caso concreto, a partir das quais é possível avaliar se os seus efeitos são benéficos

4. O número de domicílios para cada assentamento foi informado com base em dados de 2006, fornecidos pela Secretaria de Planejamento do município de Juiz de Fora em maio de 2018. Tais números só aparentam certo grau de defasagem no Alto Santo Antônio, onde é nítido o crescimento da área além dos números oficiais. 
ou maléficos para a garantia da moradia adequada e do acesso à terra urbanizada e regular à população de baixa renda (MAGALHÃES, 2019). Nesse sentido, percebemos que nem todas as etapas possuem o mesmo nível de relevância e que os maiores impactos positivos advêm do provimento de infraestrutura e serviços. É sabido que, em âmbito nacional, em muitos casos, ocorre aumento do custo de vida nos assentamentos regularizados.

Um exemplo que ilustra a afirmação acima é o estudo de Mello e Cunha (2011), em que eles discutem os efeitos da implantação de uma Unidade de Polícia Pacificadora (UPP) na favela Santa Marta, no Rio de Janeiro, assim como as intervenções promovidas em decorrência da implantação de um Posto de Orientação Urbanística e Social (POUSO) na mesma área. Os autores apontam que o fornecimento de serviços e as ações de regulamentação e fiscalização de obras provocaram diversos conflitos entre os moradores e o poder público. Isso acontece devido à necessidade de adaptação a uma nova realidade e de internalização de regras, uma vez que o processo exige que os moradores se adequem a uma série de obrigações econômicas, políticas e morais.

Em contraposição ao exemplo acima, nos casos estudados em Juiz de Fora, as tarifas sociais previstas na Lei Federal $n^{0} 10.257^{5}$ foram aplicadas e o custo de manutenção dos imóveis, aparentemente, não aumentou em proporções significativas. Quando esse aumento de custo não acontece, os impactos positivos do processo de regularização são potencializados, porque é economicamente viável que a população original permaneça na área, evitando-se o que alguns consideram como expulsão pelo mercado.

O processo de titulação é a etapa mais controversa. Apesar de os estudos de caso indicarem a sua importância em momentos de conflito, ele não é capaz de proporcionar segurança da posse per si. São conhecidas inúmeras situações em que assentamentos de baixa renda sofreram remoção forçada, ainda que os beneficiários da regularização tivessem recebido títulos fundiários juridicamente adequados. Um dos exemplos recentes mais expressivos vem da Vila Autódromo, assentamento de baixa renda na cidade do Rio de Janeiro, cuja operação de erradicação ganhou repercussão mundial em virtude de ter ocorrido no contexto das obras preparatórias para a realização das Olimpíadas de 2016. O que esse caso, ao lado de outros, sugere é que titulação não pode ser tomada como equivalente de segurança da posse, pois esta depende de uma série de condições e medidas, além e aquém da titulação, como sinaliza Rolnik (2015, p. 211-219).

5. O artigo 47 da Lei $\mathrm{n}^{\circ} 10.257$ dita que "Os tributos sobre imóveis urbanos, assim como as tarifas relativas a serviços públicos urbanos, serão diferenciados em função do interesse social” (BRASIL, 2001). 
A titulação é um componente relevante, embora não suficiente, da meta de incrementar a segurança da posse - meta que entendemos como essencial à noção de regularização fundiária, especialmente a que se pretende 'plena'. Para além dos estudos de caso, essa compreensão foi construída a partir dos referenciais teóricos mencionados. Boaventura de Sousa Santos (1988) evidencia que os próprios habitantes realizam melhorias infraestruturais nos assentamentos como uma estratégia de consolidá-los - percepção amplamente presente na literatura sobre favelas produzida ao longo do século XX. Clichevsky (2003) explora o fato de que melhorias habitacionais são comumente realizadas pelos moradores de forma independente do processo de titulação. Durand-Lasserve e Clerc (1996) e Edésio Fernandes (2005; 2007) afirmam - e ratificamos a ideia - que, para que sejam de fato uma etapa na promoção da mudança social, é fundamental que os programas de regularização fundiária estejam associados a um conjunto mais amplo de políticas públicas, diretrizes de planejamento e estratégias de gestão urbana. Edésio Fernandes (2005) relata que, na América Latina e em países de outras regiões, os programas de regularização que se basearam, em geral, na emissão de títulos de propriedade individual não chegaram a ser totalmente implementados, ou seja, não chegaram a cumprir todas as etapas da regularização fundiária plena. Em suma, asseveramos que a titulação é parte do processo (como um todo e em seu objetivo de incrementar a segurança da posse), devendo ser sempre entendida como tal.

De todo modo, é necessário demarcar a importância da titulação: em primeiro lugar, em virtude de seu caráter simbólico de legitimação social da situação de moradia nos assentamentos regularizados; em segundo lugar, em razão de facilitar o acesso aos serviços urbanos e ao uso de instrumentos jurídicos que aumentam as chances de permanência dos moradores na área, provendo-lhes instrumentos adicionais de resistência a ameaças (ao menos de algumas delas!). Assim, o título conferido proporciona maior proteção legal em relação à transmissão da posse, especialmente aquela feita por meio de herança, ponto fundamental na sociabilidade das classes populares (WEBER, 2012) ${ }^{6}$. Algumas dessas amplas funções poderiam - e até deveriam - ser também trabalhadas pela dimensão urbanística, a exemplo do que se observa na obtenção da certidão de "habite-se" e na oficialização do endereço, decorrentes, respectivamente, do reconhecimento das edificações e dos logradouros (momentos cruciais da dimensão urbanística da regularização). No tocante ao incremento da segurança da posse, parece-nos claro que a constituição do assentamento como Zona Especial de Interesse Social (ZEIS) - associada à definição de normas de uso e ocupação do solo que privilegiem os modos típicos de

6. Não se trata de algo somente dessas classes, sendo relativamente compartilhado por outros segmentos sociais. 
aproveitamento da terra das classes populares e, por fim, a medidas concretas de gestão territorial a serem adotadas pela municipalidade - é tão importante quanto o modelo de titulação a ser adotado.

A respeito desses pontos, vejamos dois exemplos. A Vila Sô Neném é uma área titulada em que os moradores ainda precisam recorrer à administração municipal para obter declaração de endereço, a partir da qual conseguem acesso a certos serviços. Já no Alto Santo Antônio, os moradores não possuem um título. Quando do interesse da administração municipal por essa área, uma declaração de endereço e de início do processo de regularização foi emitida para que eles tivessem acesso aos serviços urbanos. Com essas experiências, é possível concluir que a titulação não é, de fato, estritamente necessária para viabilizar o acesso a serviços urbanos, uma vez que essa questão foi resolvida por vias administrativas nos casos estudados, sem a dependência de um título de propriedade ou de outro direito formal sobre a terra. No âmbito conceitual e normativo7, tal relação de dependência também não vem sendo considerada necessária já há algum tempo, sendo até mesmo combatida, por representar uma perspectiva que condiciona direitos urbanos aos direitos fundiários, logo, uma visão patrimonialista que não se harmoniza com a concepção de regularização fundiária plena.

Quanto à necessidade de evitar a expulsão dos moradores do assentamento, essa ideia, por si, exprime uma intenção de tutelar o uso e a ocupação do solo na área objeto da regularização. Essa tutela, atualmente, acontece por decisões conscientes de técnicos administrativos, enquanto os moradores pouco dizem sobre o que desejam. Neste artigo, a partir dos estudos empíricos e teóricos realizados, identificamos a definição de ZEIS como uma possibilidade de fazer com que que os investimentos em prol de moradores de baixa renda permaneçam voltados a eles mesmos, na intenção de afastar as pressões do mercado imobiliário, o que constitui outra faceta importante do incremento da segurança da posse. Com esse instrumento de gestão territorial, o setor de planejamento de cada municipalidade poderia antecipar processos de valorização e elaborar legislação específica para as ZEIS, de modo a minimizar os efeitos negativos da atuação das forças de mercado sobre o processo de regularização.

A titulação não deveria ser um fator limitante para a conclusão dos processos de regularização fundiária, como vem acontecendo nos exemplos estudados.

\footnotetext{
7. É o que se pode observar num sem-número de Planos Diretores, de Leis Orgânicas municipais e de Constituições Estaduais que vêm sendo elaborados no país desde 1989. A título de exemplo, transcrevemos o art. 234, parágrafo único, da Lei Orgânica do Município do Rio de Janeiro, de 1990: "A prestação de serviços públicos à comunidade de baixa renda independerá do reconhecimento de logradouros e da regularização urbanística ou registrária das áreas e de suas construções”.
} 
Com uma compreensão mais refinada a respeito do significado e dos impactos dos processos de regularização, a administração municipal poderia racionalizar e direcionar melhor os seus esforços na etapa de titulação, maximizando os seus resultados positivos e diretos nos moradores do assentamento beneficiado, bem como no atendimento das demais dimensões da regularização - vale dizer, a física, a social e a ambiental, a depender das especificidades da área. Parece-nos claro que a implantação do modelo de regularização fundiária plena requer tanto o refinamento da compreensão de sua dimensão jurídico-dominial quanto o equilíbrio e a integração real desta última com as demais dimensões acima indicadas.

O refinamento aqui preconizado consiste mais em adaptar as ferramentas existentes do que em criar novos mecanismos totalmente "do zero". Essa adaptação requer o reconhecimento de agentes e práticas de gestão e de regulação territorial anteriormente adotadas no assentamento, tal como tem sido preconizado em diversos trabalhos, a exemplo de Magalhães (2013), Rolnik (2015) e Soto (2001). Requer, também, a revisão dos procedimentos e normas municipais, inclusive procedimentos de diálogo com os moradores, culminando numa alteração profunda no modo como a realidade urbana é trabalhada no âmbito das políticas públicas.

Com base nos pontos colocados até aqui e inspirados no estudo de avaliação da experiência brasileira sobre urbanização de favelas e regularização fundiária desenvolvido pelo Instituto Brasileiro de Administração Municipal (IBAM, 2002), na seção seguinte, sistematizamos lições, ou aprendizados, que extraímos do caso juiz-forano, a fim de que os processos de regularização fundiária possam ser continuamente aprimorados em todas as suas dimensões, no sentido de buscar sucessivas aproximações em relação ao seu ideal utópico representado pela concepção de regularização plena.

\section{A preparação e a implementação da política de regularização fundiária}

O processo de regularização fundiária começa bem antes do início das ações de campo em um determinado assentamento de baixa renda. Primeiramente, é necessário um contexto político, econômico e social favorável à incorporação dessa política entre as prioridades municipais, seguido do desenho da política - o que pode ser feito mediante um plano de regularização - e consequente elaboração da legislação disciplinadora do processo de regularização. Em segundo lugar, esse contexto precisa se manter favorável para que a implementação da política de regularização elaborada conte com recursos (orçamentários, humanos, logísticos, normativos etc.), saia de fato do papel e tenha sustentabilidade no tempo - elemento indispensável para que as ações produzam os efeitos desejados.

Entretanto, a terminologia "favorável” por si só não quer dizer muita coisa, sendo possível questionar: “favorável para quem?”. Em outras palavras, isto 
implica indagar onde está o sujeito social da regularização fundiária. Retomamos aqui nosso referencial teórico, especialmente os trabalhos de Santos (1996) e Ribeiro (2005). Ambos enfatizam a necessidade de colocar tal espécie de questão diante de todo tipo de conflito pelo direito à cidade, recordando-nos, a todo momento, que não há processo social sem sujeito e que nesse item reside a chave explicativa para os dilemas mais essenciais enfrentados em diversos cenários urbanos, a exemplo daquele demarcado pela regularização fundiária. Com efeito, em diversos municípios brasileiros, a regularização fundiária somente entrou na agenda pública em função das lutas dos movimentos de moradores contra remoções forçadas a partir do final da década de 1960, cujo corolário foi a exigência de medidas alternativas que reconhecessem a moradia popular autoproduzida (SANTOS, 1981). Em suma, trata-se de perguntar, a cada etapa da regularização, qual o papel desempenhado pelos moradores dos assentamentos a serem alcançados por esse tipo de medida, bem como por suas respectivas organizações coletivas. Esse ponto será retomado ao longo do artigo.

Aqui, fizemos o esforço de elencar e analisar diversas características políticas, institucionais, técnicas e sociais em torno da regularização, com vistas a identificar os principais fatores que demarcariam um contexto "favorável" a ela. Tais características estão sucintamente sistematizadas nesta seção na forma de pressupostos, constituindo pontos que, segundo nossa percepção, devem ser levados em conta ao planejar, preparar e conduzir processos de regularização fundiária. É um rol de pressupostos cuja elaboração foi inspirada nas experiências diretas com nosso objeto de estudo.

Para começar, vejamos alguns pressupostos políticos. O primeiro deles consiste na ideia de quebrar a dinâmica "obrista” comumente presente nas administrações municipais. Com isso, queremos dizer que, em referência não somente à regularização fundiária, mas também à política urbana de maneira geral, o setor de planejamento deve assumir papel preponderante em relação ao de obras, a fim de prevenir que as intervenções territoriais não aconteçam de forma casuística, clientelista ou com outras distorções que podem advir da centralidade do departamento encarregado pela atividade-fim. Apesar da preponderância do setor de planejamento, a relação entre ele e os demais deve se dar por meio de uma articulação cooperativa horizontal, em que os órgãos responsáveis pelo planejamento urbano, pelas obras, pela titulação etc. conversem entre si, criando condições favoráveis a um processo de regularização fundiária plena.

Como segundo pressuposto político, trazemos a questão da institucionalização da regularização fundiária. Ela é entendida como um enraizamento dessa intervenção nos âmbitos político, administrativo, orçamentário e normativo, de 
modo a conferir segurança à sua continuidade, isto é, garantir que os projetos sejam realizados em todas as suas etapas e tenham alguma probabilidade de atender ao conceito de regularização fundiária plena. É certo que a alternância político-administrativa é uma contingência inevitável e inerente ao regime democrático; o problema, porém, reside no fato de que as ações de regularização muitas vezes enfrentam rupturas administrativas que comprometem a qualidade das intervenções, passando, assim, por processos de reestruturação que afetam as áreas em meio às ações de regularização - aspecto que pode pôr em xeque investimentos já realizados e esforços de média ou longa duração.

Por fim, consideramos importante que a administração municipal estabeleça relações de apoio e parcerias com agentes da chamada sociedade civil, em especial com os segmentos organizados da população. O poder público não é capaz de conduzir, por si só, um processo de regularização fundiária plena. Para além de organizações civis em que o poder público pode se apoiar ou com elas colaborar, os moradores das áreas a serem regularizadas devem sempre ser reconhecidos como sujeitos de direito e principais beneficiários dessa intervenção, logo, são parte indispensável e essencial da regularização. Importante frisar que os moradores não constituem, necessariamente, uma unidade de interesses, o que exige o reconhecimento de sua diversidade interna de expectativas e necessidades.

Tal como a dimensão política, as questões institucionais também exercem um relevante papel. Indicamos um conjunto de pressupostos institucionais inerentes à regularização. 0 primeiro deles se refere à importância de uma engenharia financeira adequada, bem implementada e transparente. Os recursos municipais para promover um processo de regularização fundiária plena costumam ser escassos; desse modo, financiamentos integrados a outros programas são importantes meios de aumentar a capacidade financeira para investir nessas intervenções, que, por serem públicas, devem buscar ser, como sinalizado acima, transparentes e de fácil controle social.

Intimamente relacionado à preponderância que o setor de planejamento deve ter em relação ao de obras, encontra-se o segundo pressuposto institucional: previsão de recursos para a elaboração de projetos urbanos, ambientais, arquitetônicos etc. A elaboração de projeto é essencial para um planejamento adequado da intervenção. Sem isso, é comum que as necessidades da população não sejam ouvidas e correspondidas, haja desperdício de dinheiro e aumento no tempo de realização e finalização das ações. A elaboração de projeto constitui uma obrigação introduzida desde 2009 na legislação nacional de regularização fundiária (foi mantida na reforma de 2016/2017). Entendemos que esse ponto é bastante coerente com os aprendizados decorrentes da experiência de Juiz de Fora. 
O terceiro pressuposto também tem forte ligação com o anterior: disponibilidade de bases e sistemas de informação atualizados. Bases de dados desatualizadas são prejudiciais a qualquer intervenção no território urbano. No que diz respeito à regularização fundiária, elas são importantes, sobretudo, para fundamentar as escolhas técnicas das áreas a serem beneficiadas e para elaborar projetos. Esse pressuposto implica superar a ampla margem de desconhecimento sobre os assentamentos de baixa renda que paira na administração pública brasileira, do ponto de vista histórico.

Gerenciar tantas demandas institucionais não é missão simples, por isso, os próximos pressupostos institucionais se referem ao corpo técnico e à capacidade de gestão. A partir do momento em que é diagnosticada uma carência no corpo técnico-administrativo da administração municipal, surge a necessidade de adequar a dotação de recursos humanos. É comum que a administração municipal não tenha um corpo técnico com membros suficientes para executar todas as tarefas da regularização, especialmente a plena. Nesse caso, cabe-lhe a decisão de reforçar o seu corpo técnico-administrativo mediante contratação direta, nas diversas modalidades em que isso é possível, ou de abrir processos de licitação, a fim de contratar empresas e/ou organizações não governamentais para a execução das etapas de regularização. Por um lado, o reforço do corpo técnico-administrativo pode significar um maior ônus no longo prazo, devido ao pagamento dos salários de mais funcionários públicos, enquanto a contratação de organizações terceirizadas permite um gasto pontual e limitado, atrelado à entrega do processo de regularização. Por outro, a decisão pelo aumento do corpo técnico pode significar maior alinhamento e controle da condução da regularização por parte da administração, além de ser uma via capaz de gerar estruturação interna e capacitação para as próximas ações, algo que pode interferir na continuidade do processo. Considerando esses aspectos, todas as alternativas possuem potencialidades e ameaças, bem como sempre exigem que os gestores públicos ajam no sentido de minimizar problemas. Devemos observar, ainda, que, independentemente da escolha da administração, a capacidade de gerenciar projetos que integram muitas das intervenções setoriais é um quesito fundamental. Por isso, os recursos humanos precisam ser continuamente capacitados para trabalhar com diferentes frentes e dimensões em uma intervenção de regularização.

Como se vê, o corpo técnico tem um papel relevante na condução das ações de regularização, daí a necessidade de sua valorização. Entramos, assim, em nosso primeiro pressuposto técnico. No processo de planejamento das ações, a tomada de decisão a respeito de quais áreas serão beneficiadas, muito embora possua uma dimensão política inexpugnável, deve ser amplamente amparada em estudos 
técnicos, por exemplo, na montagem de uma matriz de priorização a partir de critérios físicos, socioeconômicos etc., de maneira a evitar motivações arbitrárias ou puramente eleitoreiras.

O segundo pressuposto técnico se refere ao uso adequado de instrumentos de regularização fundiária, que são numerosos na legislação brasileira, dando aos gestores um leque considerável de opções. A definição de qual deles será aplicado em cada caso deve sempre envolver a população beneficiária da regularização, além de buscar a menor burocracia e o menor tempo possível de duração do processo.

É interessante acionar, similarmente, estratégias capazes de mobilizar e potencializar o capital social existente e latente nas comunidades. Nos assentamentos estudados, uma das formas experimentadas de mobilização da população foi contratar moradores para trabalhar nas obras de urbanização. Eles também foram capacitados, o que proporcionou tanto renda quanto qualificação para o trabalho. Apostou-se, ainda, no fato de que aqueles que constroem seus ambientes tendem a cuidar e prezar por sua manutenção em bom estado.

Mais uma vez, o planejamento entra aqui em cena. Planejamento e viabilidade de ação vêm antes da legislação na regularização fundiária. Os problemas territoriais que a regularização deseja enfrentar não são resolvidos com a simples promulgação de uma lei. Para que a legislação específica ao assentamento seja elaborada, é necessário que, antes, sejam dispendidos tempo e recursos financeiros aos estudos da área, que aumentarão a viabilidade de aplicação e os efeitos positivos da própria legislação sobre o desenvolvimento do assentamento e do município. O planejamento também deve fazer parte do processo de decisão dos elementos infraestruturais. Soluções de baixo custo e com elevados níveis de durabilidade nos projetos arquitetônicos e urbanísticos são importantes, porém, o baixo custo não pode interferir na qualidade das obras realizadas. Muitas vezes, como no caso da Vila Sô Neném, logo após as obras, emergem diversos problemas estruturais devido ao uso de materiais de baixa qualidade, e quem arca com esses custos futuros são os moradores. Como muitas pessoas não possuem condições financeiras para bancar esse tipo de despesa, elas acabam voltando a habitar em um local que não lhes garante boa qualidade de vida.

Mais do que simplesmente dotar o assentamento de benefícios urbanos básicos, antes inexistentes, a infraestrutura adequada deve se relacionar com o entorno. Uma das formas de segregação espacial é representada pela discrepância na infraestrutura urbana entre áreas vizinhas. Assim, a equiparação física das infraestruturas instaladas no assentamento regularizado e em seu entorno é um fator que pode refletir positivamente na qualidade urbana da região como um todo. 
As melhorias infraestruturais são parte essencial no processo de consolidação dos assentamentos. Boaventura de Sousa Santos (1988) e Carlos Nelson Ferreira dos Santos (1981), entre outros autores, afirmam que o desenvolvimento da ocupação faz crescer os custos políticos das remoções, atuando como uma estratégia contra a remoção do assentamento e, por consequência, auxiliando na consolidação de um processo de regularização fundiária. Assim, com as melhorias infraestruturais, a sensação de segurança da posse dos moradores aumenta de tal forma que eles são induzidos a investir mais em suas habitações. Por sua vez, esses investimentos possibilitam que o assentamento se consolide cada vez mais, constituindo um ciclo virtuoso. Também contribui para esse ciclo virtuoso o fato de que, com a infraestrutura implementada, fica mais fácil aos moradores transportar material de construção para suas casas, e isso possibilita que eles mesmo agreguem novos investimentos no local.

Outro pressuposto técnico que ressaltamos é a necessidade de compatibilização das intervenções promovidas com legislação urbanística local. É uma ação crucial da dimensão urbanística da regularização, a qual não foi implementada nos casos estudados. A não execução de ações no sentido da regularização urbanística mantém o assentamento sob uma legislação inadequada à sua realidade. Com isso, a regularização fundiária não se completa e consequências negativas podem decorrer desse fato, como a diminuição da sensação de segurança jurídica e a dificuldade de acesso pleno aos serviços.

Por fim, mas não menos importantes, encontram-se os pressupostos sociais. O principal deles é a organização comunitária. Como mostram os primeiros esforços de avaliação das experiências de regularização fundiária (ARAÚJO, 1988; CLICHEVSKY, 2003), a articulação de lideranças comunitárias motivadas a alcançar benefícios comuns é um diferencial fundamental para a boa condução do processo de regularização fundiária. A participação qualificada dos moradores em todas as etapas da regularização permite a adoção de soluções mais adequadas ao assentamento. Quando ela não está presente desde o momento da preparação das intervenções, é necessário estimulá-la como um primeiro passo para a promoção do processo de regularização fundiária. Esse é um dos dilemas enfrentados pelo chamado "trabalho social" em processos de regularização: como obter uma organização comunitária em locais onde ela não existe ou não surge de forma espontânea entre a população potencialmente beneficiária? Um ponto relevante, nesse âmbito, é a denominada "superação do individualismo". A observação rigorosa das experiências juiz-foranas vem ao encontro da hipótese de que os moradores se associam em prol de melhoramentos coletivos na expectativa de que isso ofereça benefícios individuais, ou seja, a pessoa participa das ações mais pela possibilidade 
de conseguir algo de seu interesse do que pela sensação de pertencimento ao local ou ao grupo (OLSON, 1999) ${ }^{8}$. Sendo assim, motivar os moradores para que se envolvam em questões comunitárias é um desafio ao trabalho social inerente à regularização, e isso passa por mostrar a correlação entre os benefícios individuais e coletivos da intervenção.

O segundo pressuposto social é o que podemos chamar de "empoderamento" dos moradores. Nos casos estudados, uma das formas usadas para fortalecer a autonomia e a confiança dos moradores foi incentivá-los a se identificarem como corresponsáveis pela intervenção. Eles, ao perceberem falhas, acionavam os técnicos da prefeitura para que resolvessem o problema com a empresa contratada. De fato, quando se sentem corresponsáveis, os moradores tendem a buscar o melhor para sua área e a notar como se beneficiam das intervenções. A manutenção das intervenções realizadas vem como consequência dessa ação.

Outro pressuposto é a criação de cursos de capacitação para os moradores - ação que também pode atuar como fator de "empoderamento" dos sujeitos. Independentemente do eixo a que os cursos se destinam (geração de emprego e renda, ambiental, social etc.), é relevante que eles sejam realizados no assentamento, em horário adequado ao público-alvo. Caso contrário, pode-se ter como resultado altas taxas de evasão, como identificado no caso do Alto Santo Antônio.

Um último pressuposto social é a capacitação e familiarização dos moradores a respeito da dimensão jurídico-dominial, de modo que a regularização tenha, entre seus resultados, a apropriação, ainda que relativa, de seu instrumental jurídico por parte dos beneficiários. Vale observar que, embora não compreendam por completo a dimensão jurídica envolvida na regularização, os moradores dos assentamentos comumente a veem como necessária para o acesso a serviços e ao mercado em geral.

\section{O momento "pós-obra": buscando consolidar os resultados da regularização}

A pesquisa empírica que embasou este artigo ocorreu em áreas de baixa renda onde os processos de regularização fundiária já haviam sido findados há dez anos ou mais. Esse tempo foi considerado suficiente para avaliar os resultados

8. Tomando por base os estudos de Olson (1999, p. 18), quando da formação de grupos, "a atração que exerce a afiliação a um grupo não é tanto pela sensação de pertencer, mas mais pela possibilidade de conseguir algo através desse pertencer”. Segundo o autor, o envolvimento ocorre na medida em que cada um dos membros do grupo, ou ao menos um deles, acha que seu ganho pessoal ao obter o benefício coletivo irá exceder o custo total de se envolver, trabalhar pela causa e prover determinada quantidade desse benefício. 
obtidos pela regularização ${ }^{9}$. Ao longo dos trabalhos de campo, tanto os técnicos da prefeitura - responsáveis pela condução do processo de regularização - quanto os moradores identificaram a descontinuidade das ações do poder público nas áreas como um fator que impossibilitou a consolidação da regularização. Isso nos permitiu um novo esforço de sistematização; dessa vez, indicamos lições que envolvem fatores políticos, institucionais, técnicos, sociais, econômico-financeiros e socioambientais relativos ao período posterior à conclusão da intervenção, o que os técnicos ligados à regularização costumam chamar de "pós-obra".

Iniciamos com as lições institucionais. Uma primeira lição é referente à ação continuada do poder público no assentamento alcançado pela regularização. Percebemos a necessidade de uma articulação continuada, uma vez que as ações não acabam no momento da conclusão da intervenção de regularização fundiária, mas se estendem para a gestão de uma área, conforme se pretende na regularização, plenamente incorporada à cidade no período pós-intervenção. Esse período exige investimentos públicos de manutenção, adequação ou mesmo de ampliação das infraestruturas, dos equipamentos e serviços instalados durante a regularização, assim como ocorre em relação ao conjunto da cidade. Isso também vale para a legislação estabelecida inicialmente para o assentamento, a qual demanda revisões periódicas. Por exemplo: quando há alguma legislação preexistente, esta pode ter sido consolidada sob condições políticas e culturais que não são mais válidas no exato momento da regularização, precisando, por esse motivo, ser revista (ROLNIK, 1997). Ou ainda: quando há a introdução de uma legislação urbanística específica em áreas que nunca foram palco desse tipo de ação, costuma-se ocorrer, rapidamente, a emergência de um conjunto de conflitos que demandam ajustes em prazos não muito longos.

A fim de que os investimentos e revisões sejam identificados, indicamos a próxima lição institucional, qual seja, o poder público local deve implementar sistemas de monitoramento e avaliação. O acompanhamento dos resultados é importante para que haja a devida correção de problemas decorrentes da maneira como foi realizada a regularização. Nesse sentido, é relevante que ele inclua em seu escopo a avaliação periódica da manutenção da demarcação dos assentamentos regularizados como ZEIS ou sob alguma legislação protetiva que favoreça o interesse social. Muitos especialistas (do meio acadêmico ou da gestão pública), como Bacelete (2009) e Alfonsin (2000), recomendam que a área regularizada permaneça

9. No Estatuto da Cidade, dez anos é o período máximo para que os Planos Diretores municipais sejam revisados. Sendo assim, consideramos esse período como suficiente para a consolidação de uma política urbana. 
demarcada como interesse social - uma estratégia para evitar descaracterização, mudanças súbitas no seu padrão de uso e ocupação do solo, valorização exagerada da área, com a consequente expulsão dos moradores. Trata-se de uma avaliação que deve ser feita cuidadosamente, tendo em conta as dinâmicas locais. Assim como na maioria das situações enfrentadas pela gestão urbana, o sistema normativo nacional e local permite distintas soluções e arranjos institucionais, com alternativas em relação às ZEIS.

Passemos às lições técnicas. Nelas, agrupamos um conjunto de percepções que envolvem os instrumentos de regularização fundiária. Destacamos a importância de se reconhecer, no momento do desenho e da aplicação dos instrumentos urbanísticos, a necessidade de permitir a transmissão da titularidade dos imóveis por parte dos moradores. Na medida em que a mobilidade habitacional está presente mesmo antes da regularização - característica intrínseca da vida urbana (ABRAMO, 2003) -, como regra, não cabe à proposta da regularização restringi-la, ressalvadas situações excepcionais e temporárias. Isso não implica a adoção automática da titulação por meio da propriedade plena e individual dos imóveis regularizados, posto que outras modalidades de titulação também permitem a transmissibilidade. Junto disso, há que se considerar tanto as expectativas dos moradores quanto a possibilidade de a modalidade adotada expô-los, em demasia, às pressões das forças de mercado. A partir dessas questões, distinguimos uma tripla função do processo de titulação: aumentar a sensação de segurança da posse, diminuir as possibilidades de expulsão dos moradores e permitir a mobilidade habitacional.

Um segundo ponto que nos chamou especial atenção, e ainda está incluído nas lições técnicas, são as modalidades coletivas de titulação. Uma dimensão que singulariza a experiência estudada é a figura da usucapião coletiva, figura que reputamos ainda carecer do devido amadurecimento, em termos conceituais, normativos e até de práticas e experiências. A diretiva de se buscar "soluções coletivas para problemas coletivos” constitui uma das apostas do Estatuto da Cidade e de toda a trajetória das políticas de regularização fundiária no Brasil, um dos muitos países do Sul global que enfrenta problemas macroestruturais de acesso à terra. Assim, pensamos ser fundamental refletir sobre avanços e dificuldades dessas soluções, ainda mais no período que sucedeu a edição da MP 759, de 2016 - convertida na Lei Federal $n^{0}$ 13.465, de 2017 -, que exacerbou a aposta individualista, viés que se explicita na maneira como desenhou a figura da Reurb. ${ }^{10}$

10. Trata-se de um nomen juris para designar a regularização fundiária e suas modalidades, adotado na mencionada Lei Federal $n^{0}$ 13.465/17. 
No caso estudado, na formação do condomínio especial de que trata o art. 10, e seus parágrafos, do Estatuto da Cidade ${ }^{11}$, atribuiu-se uma fração ideal à prefeitura, a fim de legitimar a sua propriedade das áreas de uso comum do assentamento regularizado, as quais constituem logradouros públicos, praças etc. Essa medida parece ajudar a ultrapassar o problema das vedações legais (reais ou supostas) para que o poder público faça investimento numa área que, tecnicamente, seria privada, facilitando a gestão pública da área regularizada. É uma saída que também possui a virtude de reafirmar o dever municipal de manutenção dos investimentos feitos. Contudo, a análise do processo de regularização evidenciou que houve um problema: no momento do registro, foi concedida idêntica fração ideal a todos, inclusive para a prefeitura, que recebeu uma fração menor do que a parcela efetiva de áreas que ficaram sob sua administração. Como até 2016 a usucapião coletiva dependeu exclusivamente de decisão judicial, a cautela quanto ao estabelecimento adequado das frações concedidas aos moradores e à administração deve estar presente desde a petição inicial da ação promovida pelos usucapientes ou, na pior das hipóteses, ser equacionada durante a tramitação processual, mediante o chamamento da prefeitura ao processo judicial, a partir de seu primeiro momento - providência que, na prática, se revela indispensável à efetividade dessa espécie de processo.

Além de uma melhor gestão institucional e do uso adequado dos instrumentos urbanísticos, algumas lições socioambientais devem ser assinaladas. Em primeiro lugar, indicamos a relevância da inclusão de componente de educação sanitária e ambiental na regularização. Tratar a dimensão ambiental é fundamental não só para garantir um ambiente ecologicamente equilibrado, mas também para aumentar o bem-estar dos moradores. Ainda nesse sentido, observamos a importância de projetos que tragam as pessoas para os espaços públicos. Nem sempre as intervenções preveem espaços de esporte, lazer e/ou de convivência para a população, e este foi um fator bastante enfatizado nas avaliações colhidas com os moradores ao longo dos trabalhos de campo. A intervenção, para garantir a boa qualidade de vida, deve ir além da infraestrutura básica, provendo, também, infraestrutura para atividades coletivas. Mais que isso: o trânsito de pessoas nas ruas ainda alcança

11. Merecem transcrição os três últimos parágrafos, que versam diretamente sobre o aspecto em discussão: “§ $3^{\circ} \mathrm{Na}$ sentença, o juiz atribuirá igual fração ideal de terreno a cada possuidor, independentemente da dimensão do terreno que cada um ocupe, salvo hipótese de acordo escrito entre os condôminos, estabelecendo frações ideais diferenciadas. $\S 4^{\circ} \mathrm{O}$ condomínio especial constituído é indivisível, não sendo passível de extinção, salvo deliberação favorável tomada por, no mínimo, dois terços dos condôminos, no caso de execução de urbanização posterior à constituição do condomínio. $\S 5^{\circ}$ As deliberações relativas à administração do condomínio especial serão tomadas por maioria de votos dos condôminos presentes, obrigando também os demais, discordantes ou ausentes". 
fatores como maior integração dos moradores e diminuição da violência, tal como sugerido por Jacobs (2011).

Para que todas as lições acima possam ser viabilizadas, trazemos à baila as lições econômico-financeiras. Como primeira lição, estão os mecanismos de recuperação de custos e investimentos do programa/projeto de regularização. Apesar da impopularidade e da ausência de tradição de aplicação desse tipo de medida no país, especialmente em áreas de baixa renda, a falta desses mecanismos põe em risco a manutenção, ampliação e replicação das ações de regularização fundiária por parte da prefeitura - agente promotor da ampla maioria das ações de regularização. O tema possui interface com o problema do aumento dos custos de manutenção do imóvel como consequência da regularização, o que diminui o interesse da população em torno dessa intervenção, deixando de vê-la como benefício (MELLO; CUNHA, 2011). Parece-nos indispensável a ponderação de todos os aspectos envolvidos, sobretudo a capacidade contributiva dos beneficiários da regularização, geralmente, já penalizados pela regressividade do sistema tributário no país.

Uma segunda lição econômico-financeira é a definição de políticas tarifárias para a oferta de serviços urbanos, específica e compatível com a capacidade de pagamento da comunidade. As chamadas "tarifas sociais", previstas em lei e aplicadas nos casos estudados, constituem fator que ajuda a garantir a permanência dos moradores na área após a intervenção, ao evitar o aumento do custo de vida acima da capacidade de pagamento deles.

Falar da previsão de recursos orçamentários necessários à adequada operação de equipamentos públicos ofertados, em particular os sociais, pode parecer um tanto quanto óbvio, mas fica como terceira lição. Aplica-se à administração municipal e sua capacidade de manter as melhorias implementadas.

A quarta lição pode ser situada no componente de geração de emprego e renda, essencial para aumentar as possibilidades de desenvolvimento socioeconômico e urbanístico decorrentes da regularização e da própria realização de melhorias habitacionais por iniciativa dos moradores. Entretanto, trata-se de um componente difícil de ser atendido pela municipalidade, em função até mesmo das profundas mutações que o mundo do trabalho vem enfrentando. Um dos meios aplicados nos casos analisados foi a oferta de cursos profissionalizantes, os quais, da forma como foram implementados, não obtiveram muitos impactos positivos. Para obter melhores resultados, uma das medidas corretivas seria oferecê-los no próprio assentamento, em horário adequado ao público-alvo, e atrelá-los a um programa do poder público de efetiva inserção dos cursistas no mercado de trabalho.

Finalizamos com a quinta lição econômico-financeira, que, em certa medida, complementa a anterior, a saber, a oferta de microcrédito, no sentido de estimular 
o desenvolvimento de microempreendimentos comunitários. Ou seja, não basta incentivar financeiramente a criação desse tipo de empreendimento, é necessário fornecer, também, condições materiais imediatas para o seu surgimento e para a sua sustentação temporal e econômica.

\section{Para concluir (ou não!)}

Neste artigo, intentamos refletir a respeito de como vem sendo tratada a política de regularização fundiária de interesse social na esfera municipal, a partir do estudo das experiências do município de Juiz de Fora, Minas Gerais. Buscamos, em especial, analisar, de maneira contextualizada, a noção de regularização fundiária plena e suas condições de viabilidade.

Em nossa avaliação, ficou patente a necessidade de uma revisão dos processos de desenho, implementação e acompanhamento da política de regularização. Considerando isso, foram elencados pressupostos e lições recolhidas da experiência juiz-forana, a fim de referenciar empiricamente o debate e subsidiar futuras experiências, cumprindo, portanto, o almejado papel teórico-prático da pesquisa.

As experiências de Juiz de Fora ficaram aquém do atendimento do conceito de regularização fundiária plena. Em geral, as ações giraram em torno do provimento de infraestruturas, implementadas paulatinamente nos assentamentos; quando da finalização delas, iniciava-se o processo de titulação. Trata-se de duas frentes executadas de modo fragmentado, sem articular as quatro dimensões da regularização plena (jurídico-dominial, urbanística, ambiental e físico-social). Apesar de concluirmos que as experiências estudadas empiricamente não atendem ao conceito de regularização fundiária plena, observamos que elas representam, ainda assim, um importante subsídio para o debate de temas intrínsecos ao processo de revisão do referido conceito, na medida que possuem resultados ainda não devidamente considerados nas avaliações de experiências associadas ao tipo de regularização fundiária aqui trabalhado - avaliações que ainda tendem a medir o (in)sucesso da regularização em função da quantidade de títulos fundiários emitidos.

Consideramos que o conceito de regularização fundiária plena adotado na Lei Federal $n^{0}$ 11.977, de 2009, traduz um importante esforço no sentido de efetivar, jurídica e materialmente, cláusulas constitucionais fundamentais, como o direito social à moradia, a função social da propriedade e o direito ao meio ambiente ecologicamente equilibrado. Entretanto, à luz da experiência estudada - e de outras no Brasil -, não é difícil perceber que as quatro dimensões da regularização plena ficam aquém do idealizado, quando as ações são inscritas no território. Esse é o descompasso que procuramos explicitar e examinar ao longo deste artigo, por intermédio de alguns grandes eixos de reflexão, tais como: segurança da posse; 
custos de manutenção; valorização fundiária; transmissão de titularidade do imóvel regularizado; acesso à infraestrutura e a serviços no assentamento; descontinuidade das ações públicas; papel dos beneficiários.

Num balanço mais amplo, um ponto crucial na qualificação das experiências é o papel dos beneficiários, reais ou supostos, da regularização, ou seja, os moradores dos assentamentos. A recorrente visão deles como "parceiros" da regularização parece-nos insuficiente para dar conta de seu reconhecido protagonismo no âmbito do discurso, apresentando-se mais como uma versão reducionista. Tal noção reafirma, antes, uma concepção um tanto autocrática, historicamente presente nas relações entre Estado e classes empobrecidas, tradição que não parece ainda ter sido devidamente superada no desenho de ações, projetos, programas e políticas de regularização. Essa superação, caso ocorresse, certamente faria com que os conceitos que tematizam as relações entre os principais agentes da regularização fossem amplamente redimensionados, incluindo nelas algo que vai além - e que é de natureza diversa - da mera "parceria". Notamos nesse problema um dos desafios estruturais para a atualização do conceito de regularização fundiária plena.

Uma possível atualização da pesquisa que deu base a este artigo consistiria numa revisita à experiência de regularização fundiária plena, a fim de analisá-la em confronto com as recentes modificações na legislação nacional a respeito do tema, introduzidas a partir de 2016 com a Medida Provisória $n^{0}$ 759, que buscou reconfigurar amplamente o modelo de regularização fundiária adotado no país. Em um momento de debates acerca da Lei Federal $n^{0}$ 13.465/17 e dos decretos regulamentares que vieram em sua esteira, tal exercício poderia servir de parâmetro para avaliar as mudanças normativas promovidas nos últimos cinco anos, período visto por alguns como um novo ciclo da macropolítica nacional, demarcado pelos governos de Michel Temer e Jair Messias Bolsonaro, periodização que vemos como igualmente válida para a política urbana e, especialmente, para a de regularização fundiária. Uma avaliação desse tipo mostra-se necessária, dado que a legislação vigente é objeto de diversas controvérsias, tendo sido implementada a partir de uma Medida Provisória, sem grandes debates abertos com a sociedade e sem o devido processo - técnico e sociopolítico - de maturação. Ela também é marcada por uma ruptura significativa com o processo de acumulação conceitual e experimental que vinha sendo desenvolvido no país desde a década de 1960, em que pesem as contradições dessa experiência. ${ }^{12}$

12. Tal demarcação toma como base o aparecimento da expressão regularização fundiária na legislação brasileira, via Estatuto da Terra (Lei Federal $n^{\circ}$ 4.504, de 1964), seguida de sua transposição ao ambiente urbano nas décadas de 1970 e 1980 a partir do BNH, da Lei Federal nº 6.766 de 1979, e de experiências municipais pioneiras. 
Por outro lado, as intervenções no sentido da regularização fundiária vêm se desenvolvendo no país de maneira não homogênea e não linear. Isso sugere que, apesar de suas deficiências, elas são objeto de disputa entre distintas concepções político-ideológicas e que interferem de modo relevante no status da questão fundiária - questão cuja centralidade marca a história brasileira desde o período colonial. Sendo assim, estudos que visam problematizar elementos sensíveis relacionados à compreensão e viabilidade dos conceitos-chave que lhes servem de base, como é o caso da noção de regularização fundiária plena aqui debatida, se mostram cada vez mais importantes e urgentes.

Tendo em vista o confronto entre o conjunto de problemas e de reflexões que emergiram do esforço de análise do material empírico e o repertório teórico utilizado como referência para pensar a regularização fundiária, fica-nos evidente que há um gap entre teoria e prática. Tal descompasso pode ser observado, de um lado, na dificuldade de fazer com que as experiências concretas de regularização incorporem e materializem compreensões já razoavelmente amadurecidas no campo especulativo. De outro, essa descontinuidade se manifesta no sentido oposto, isto é, na limitação das produções teóricas, as quais precisam tematizar e ocupar-se das questões reais que marcam as experiências de regularização, estruturando explicações e interpretações a respeito dessas questões e indicando pistas para os almejados saltos de qualidade nas práticas concretas - algo que legitimamente se espera de trabalhos científicos.

\section{Referências}

ABRAMO, P. A teoria econômica da favela: quatro notas sobre a localização residencial dos pobres e o mercado imobiliário informal. ABRAMO, P. A. (Org.). A cidade da informalidade: o desafio das cidades latino-americanas. Rio de Janeiro: 7 Letras, 2003.

ALFONSIN, B. de M. O significado do Estatuto da Cidade para os processos de regularização fundiária no Brasil. In: ROLNIK, R. (Org.). Regularização fundiária plena: referências conceituais. Brasília: Ministério das Cidades, 2007, p. 69-98.

. Políticas de regularização fundiária: justificação, impactos e sustentabilidade. In: FERNANDES, E. (Org.). Direito Urbanístico e Política Urbana no Brasil. Belo Horizonte: Del Rey, 2000. p. 195-267.

ANTÃO, R. C. do N. Regularização fundiária e federalismo: uma análise da política legislativa dos municípios de São Paulo. Anais do XVII ENANPUR, São Paulo, v. 17, n. 1, 2017. Disponível em: http://anais.anpur.org.br/index.php/anaisenanpur/article/ view/2311/2290

ARAÚJO, M. S. M. de. Possibilidades e limites de uma política pública habitacional: o programa “Cada Família, Um Lote”. Dissertação de Mestrado submetida ao Programa de PósGraduação em Planejamento Urbano e Regional, da Universidade Federal do Rio de Janeiro. Rio de Janeiro, 1988. 
BACELETE, G. G. Direito à moradia: regularização fundiária de favelas. Revista USCS - Direito v. 10, n. 16, p. 69-83, jan.jun.2009.

BRASIL. Lei $\mathrm{n}^{\circ} 10.257$ de 10 de julho de 2001. Estabelece diretrizes gerais da política urbana. Brasília, DF: Diário Oficial da União, 2001. Disponível em: http://www.planalto.gov.br/ ccivil_03/leis/LEIS_2001/L10257.htm. Acesso em: 1 nov. 2015.

Lei $\mathrm{n}^{0}$ 11.977, de 7 de julho de 2009. Dispõe sobre o Programa Minha Casa, Minha Vida: PMCMV e a regularização fundiária de assentamentos localizados em áreas urbanas, Brasília, DF: Diário Oficial da União, jul. 2009. Disponível em: http://www.planalto. gov.br/ccivil_03/_ato2007-2010/2009/lei/111977.htm. Acesso em: 26 mar. 2020.

CLICHEVSKY, N. Pobreza y acceso al suelo urbano: Algunas interrogantes sobre las políticas de regularización en América Latina. Santiago de Chile: Naciones Unidas, 2003.

DURAND-LASSERVE, A.; CLERC. V. Regularization and integration of irregular settlements: lessons from experience. Urban Management and Land, n. 6. Kenya: UNDP/UNCHS/ World Bank, 1996.

FERNANDES, E. Aspectos jurídicos de los programas de regularización de la tenencia de la tierra urbana en Latinoamérica. In: PATIÑO, A. R. (Org.). Espacios urbanos no con-sentidos. Medellín: [s.n.], 2005.

Regularização de assentamentos informais: o grande desafio dos municípios, da sociedade e dos juristas brasileiros. Regularização fundiária plena: referências conceituais. Brasília: Ministério das Cidades, 2007, p. 18-33.

GRANJA, L. S. Regularização fundiária urbana em assentamentos de baixa renda: Avaliando experiências a partir do caso de Juiz de Fora (MG). 250 f. Dissertação (Mestrado em Planejamento Urbano e Regional). Instituto de Pesquisa em Planejamento Urbano e Regional (IPPUR), Universidade Federal do Rio De Janeiro. Rio de Janeiro. 2019.

IBAM. Instituto Brasileiro de Administração Municipal. Estudo de Avaliação da Experiência Brasileira sobre Urbanização de Favelas e Regularização Fundiária. Relatório Final, v. I: Resultados das Análises. Rio de Janeiro: [s.n.], 2002.

JACOBS, J. Morte e vida de grandes cidades. 3a ed. São Paulo: Martins Fontes, 2011.

JUIZ DE FORA (MG). Centro de Pesquisas Sociais da Universidade Federal de Juiz de Fora. Proposta de Plano Municipal de Habitação: Componente A3 do PEMAS. Juiz de Fora: Centro de Pesquisas Sociais da Universidade Federal de Juiz de Fora, 2007.

MAGALHÃES, A. F. O direito das favelas. Rio de Janeiro: Letra Capital, 2013.

. Existem instrumentos urbanísticos “progressistas” ou "regressistas"? Reflexões sobre uma possível "entrada” para pensar criticamente o Direito Urbanístico In: SOUSA JR., J. G. de. O Direito Achado na Rua. Vol. 9: Introdução crítica ao Direito Urbanístico. Brasília: Universidade de Brasília, 2019, v.1, p. 109-116.

MELLO, M. A. da S.; CUNHA, N. V. da. Novos conflitos na cidade: A UPP e o processo de urbanização na favela. Revista de Estudos de Conflitos e Controle Social, Rio de Janeiro, v. 4, n. 3, p. 371-401, 2011. 
OLSON, M. A lógica da ação coletiva: os benefícios públicos e uma teoria dos grupos sociais. São Paulo: Edusp, 1999.

PERLMAN, J. E. O mito da marginalidade: favelas e política no Rio de Janeiro. Rio de Janeiro: Paz e Terra, 1977.

RIBEIRO, A. C. T. Dimensiones culturales de la ilegalidad. In: PATIÑO, A. R. (Org.). Espacios urbanos no con-sentidos. Medellín: [s.n.], 2005.

ROLNIK, R. A Cidade e a Lei: Legislação, política urbana e territórios na cidade de São Paulo. São Paulo: Studio Nobel: FAPESP, 1997.

. A guerra dos lugares: a colonização da terra e da moradia na era das finanças. São Paulo: Boitempo, 2015.

ROY, A. Slumdog Cities: Rethinking Subaltern Urbanism. International Journal of Urban and Regional Research, v. 35, n. 2, p. 223-238, 2011.

Urban Informality: Toward an epistemology of planning. Journal of American Planning Association, v. 71, n. 2, p. 147-158, 2005.

SANTOS, B. de S. O discurso e o poder: ensaio sobre a sociologia da retórica jurídica. Porto Alegre: Sergio Fabris, 1988.

. Uma cartografia simbólica das representações sociais: Prolegómenos a uma concepção pós-moderna do Direito. Revista Brasileira de Ciências Criminais, v. 4, n.13, jan/ mar, 1996. p. 253-277.

SANTOS, C. N. F. dos. Movimentos sociais urbanos. Rio de Janeiro: Zahar, 1981.

SOTO, H. de. O mistério do capital: porque o capitalismo dá certo em países desenvolvidos e fracassa no resto do mundo. Rio de Janeiro: Record, 2001.

WEBER, A. de V. Transmissão de patrimônio habitacional em favelas. Niterói: Eduff, 2012.

YIFTACHEL, O. Critical theory and "gray space". In: BRENNER, N.; MARCUSE, P.; MAYER, M. (eds.) Cities for people, not profit: critical urban theory and the right to the city. London e New York: Routledge, 2011. 


\section{Laura Santos Granja}

Mestre em Planejamento Urbano e Regional (UFRJ-IPPUR, 2019). Graduada em Arquitetura e Urbanismo (UFJF, 2016), com um ano de intercâmbio acadêmico (LUH-Alemanha, 2014). Docente no curso de Arquitetura e Urbanismo do Centro Universitário do Sudeste Mineiro desde 2019, até o momento da aprovação deste artigo.

Email: lauragranja@icloud.com

ORCID: 0000-0003-2292-2535

Contribuição de autoria: conceituação; análise formal; obtenção de financiamento; investigação/pesquisa; metodologia; administração do projeto; escrita - primeira redação; escrita - revisão e edição.

\section{Alex Ferreira Magalhães}

Doutor em Planejamento Urbano e Regional (UFRJ-IPPUR, 2010). Pós-Doutoramento no Centro de Estudos Sociais, Universidade de Coimbra (2018-2020). Credenciado no Programa de Pós-Graduação em Planejamento Urbano e Regional (docente permanente) e Graduação em Gestão Pública. Pesquisador-Bolsista FAPERJ, Programa Jovem Cientista do Nosso Estado (2016-2019). Livros publicados: O Direito das Favelas (Letra Capital, 2013); Sociologia do Direito: o pluralismo jurídico em Boaventura de Sousa Santos (Ed. UFRJ, 2014). Integrante da Diretoria do Instituto Brasileiro de Direito Urbanístico (2014-2017). Fundador e Diretor do Laboratório de Estudos das Transformações do Direito Urbanístico Brasileiro (LEDUB).

Email: alexmagalhaes@ippur.ufrj.br

ORCID: 0000-0002-6444-3252

Contribuição de autoria: conceituação; análise formal; metodologia; supervisão/ orientação; escrita - primeira redação; escrita - revisão e edição. 
Submissão: 16 de maio de 2020.

Aprovação: 10 de junho de 2021.

Como citar: GRANJA, L. S.; MAGALHÃES, A. F. Condições de viabilidade para a regularização fundiária plena: uma problematização a partir da experiência de Juiz de Fora (MG). Revista brasileira de estudos urbanos e regionais. v. 23, E202122pt, 2021. DOI 10.22296/2317-1529.rbeur.202122pt.

Artigo licenciado sob Licença Creative Commons CC BY 4.0.

https://creativecommons.org/licenses/by/4.o/deed.pt_BR 